\title{
Detection of "Exotic" Dopant-Related Macrodefects in Vapour Grown CdTe:Cr Single Crystals
}

\author{
V.D. POPOVYCH ${ }^{a *}$ AND P. SAGAN ${ }^{b}$ \\ ${ }^{a}$ Department of Fundamental Technologies, Ivan Franko Drogobych State Pedagogical University, \\ 24 Ivan Franko str., 82100, Drogobych, Ukraine \\ ${ }^{b}$ Centre for Innovation and Transfer of Natural Sciences and Engineering Knowledge, University of Rzeszów, \\ S. Pigonia 1, 35-959 Rzeszów, Poland
}

(Received April 19, 2015; in final form November 16, 2015)

SEM observation of non-typical macrodefects in the form of needle-like second phase particles in highly doped CdTe:Cr single crystals, grown by the modified physical vapour transport method, was reported. They form regular network parallel to the $\{111\}$ and $\{100\}$ planes. In the combined analyses using energy dispersive X-ray profiling and high-angle annular dark-field elemental mapping, it has been determined that the observed needle-like aggregates are composed of $\mathrm{Cr}-\mathrm{Te}$ intermetallic compound, most probably cadmium doped $\mathrm{Cr}_{3} \mathrm{Te}_{4}$.

DOI: $10.12693 /$ APhysPolA.129.49

PACS: 61.50.-f, 61.72.--y, 61.72.Vv

\section{Introduction}

Cadmium telluride is a well-known compound semiconductor, which is intensively used as a material for uncooled radiation detectors, photorefractive and electrooptic components, laser windows and substrates for fabrication of IR-source devices [1]. All above applications require homogeneous single crystalline samples with minimum amount of extended and bulk defects. However, structural quality of CdTe crystals suffers from the presence of a considerable number of second phase particles $[2,3]$. Due to the peculiar thermodynamic properties of CdTe (higher retrograde solid solubility of Te compared with that of $\mathrm{Cd}$ and, inversely, much higher partial pressure of metal constituent at applied growth temperature leading to the $\mathrm{Cd}$ loss during growth run [4]) tellurium inclusions and/or precipitates are commonly present in the as-grown crystals [5-9], although cadmium macrodefects were also observed in the material obtained under Cd-rich conditions $[10,11]$. At the same time, extrinsic second phase separation was more rarely reported in CdTe crystals [12-16].

In this paper we present the results of preliminary studies of unusual dopant-related macrodefects in vapourgrown $\mathrm{CdTe}$ :Cr single crystals using scanning electron microscopy (SEM), scanning transmission electron microscopy (STEM), energy dispersive X-ray (EDX) and high-angle annular dark-field (HAADF) analyses. Cadmium telluride doped with chromium has attracted attention of researchers as material for tunable nearinfrared lasers [17] and as perspective diluted magnetic semiconductor (DMS) for applications in spin-dependent electronics [18].

\section{Experimental and results}

Investigated crystals were highly doped CdTe:Cr single crystals obtained by the modified physical vapour

\footnotetext{
*corresponding author; e-mail: vpopovych@yahoo.com
}

transport (PVT) method [16]. The charge for crystal growth were prepared from the $(\mathrm{Cd}, \mathrm{Cr}) \mathrm{Te}$ polycrystalline ingots with 2.5 and 5 at.\% of chromium in the initial feed synthesized at the temperature as high as $1300^{\circ} \mathrm{C}$. As-grown crystals were cleaved along the $\{110\}$ crystalline planes into the wafers. Samples were prepared by chemo-mechanical polishing of the (110)-oriented surface of the wafers with $5 \%$ bromine solution in the ethyleneglycol-dimethylformamide mixture. Morphology of both cleaved and polished surfaces were examined using Tescan Vega 3 scanning electron microscope equipped with EDX-based Bruker Quantax microanalysis system.

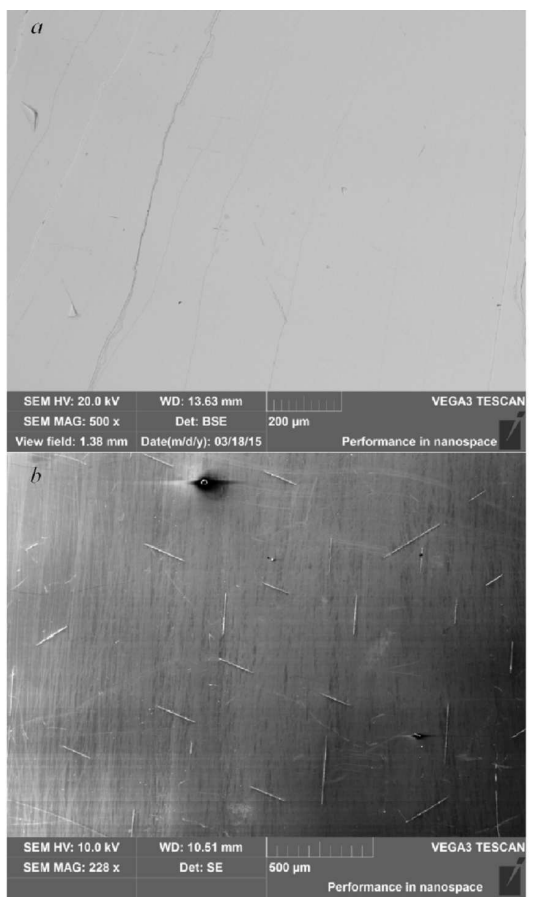

Fig. 1. (110)-oriented surface of CdTe:Cr single crystal grown from the charge with 5 at. $\%$ of $\mathrm{Cr}$ in the initial feed: (a) cleaved, (b) chemo-mechanically polished with second phase macrodefects. 
The cleaved crystal surfaces were smooth, flat and mirror-like with sets of terraces but with no visible second phase aggregates (Fig. 1a). After polishing, a number of macrodefects appeared on the surfaces (Fig. 1b). Besides well-known near isometric sub- $\mu \mathrm{m}$ particles, unusual type of defects were observed in the form of needles with the thickness of several hundred nm and up to several hundred $\mu \mathrm{m}$ long. They are arranged in the sets of parallel strips along three different directions. The angle between the directions was found to be about $70^{\circ} 30^{\prime}$ and $54^{\circ} 50^{\prime}$ indicating that the needle-like defects are aligned parallel to the $\{111\}$ and $\{100\}$ planes of the zinc-blende structure [19]. It is worth noting that such macrodefects were not observed in the CdTe:Cr crystals grown from the charge with lower chromium content suggesting that these defects are caused by dopant separation.
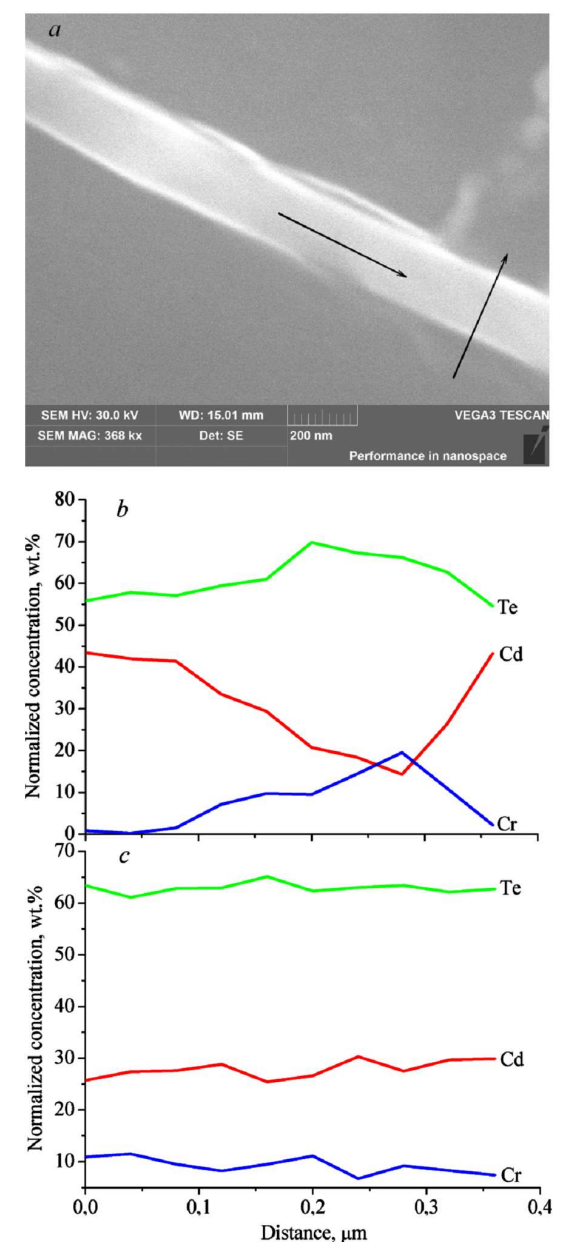

Fig. 2. EDX profiles along (b) and perpendicular (c) to the needle-like defects (a) on the chemo-mechanically polished (110)-oriented surface of the singe crystal grown from the charge with 5 at. $\%$ of $\mathrm{Cr}$ in the initial feed.

In order to identify the distribution of $\mathrm{Cd}$, $\mathrm{Te}$ and $\mathrm{Cr}$ in the observed defects, EDX profiling was done along the needle axis as well as in the direction perpendicular to the needle, as it is shown in Fig. 2a. It is clear from Fig. $2 \mathrm{~b}$ that tellurium and chromium concentrations change simultaneously, reaching at the needle position the values much higher than those in the surrounding crystalline matrix. In contrast, cadmium content behaves in the opposite way decreasing toward this defect. At the same time, the change of composition along the needle axis does not reveal any distinct trend (Fig. 2c). It can be inferred from the profiles that second phase defects are enriched with dopant, probably in the form of $\mathrm{Cr}-\mathrm{Te}$ intermetallic compound. However, correct identification of the phase is hindered due to possible excitation of characteristic X-rays in the neighboring crystal areas, which can contribute to the recorded EDX signals.

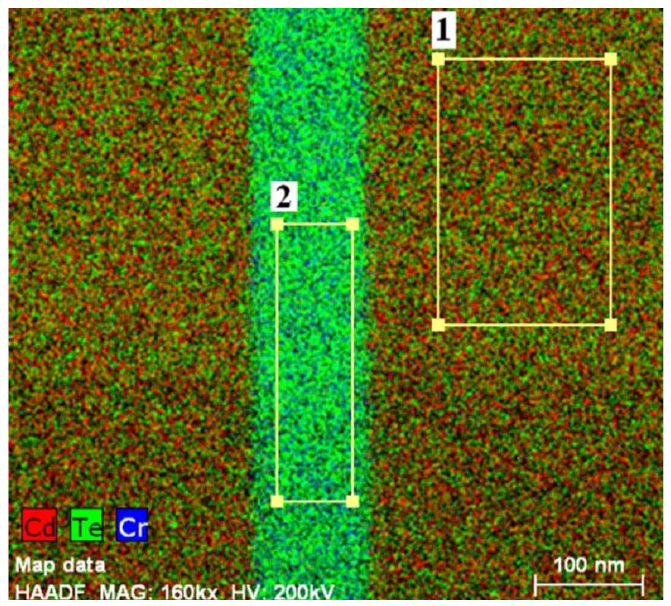

Fig. 3. Map of elements for the chemo-mechanically polished $\{110\}$ surface of the single crystal, grown from the charge with 5 at.\% of $\mathrm{Cr}$ in the initial feed.

In order to confirm the above suggestion about the nature of the extended defects, the lamellar was prepared for STEM investigations by thinning of the sample in the vicinity of one of the needle using $\mathrm{Ga}^{+}$beam of Quanta 200i SEM-FIB microscope. Elemental mapping was done in the defect and in surrounding crystal bulk by the HAADF STEM method using FEI Tecnai Orisis TEM/STEM microscope (Fig. 3). The results of quantitative determination of the composition are given in Table I. Considering the molar $\mathrm{Cr} / \mathrm{Te}$ ratio in the defect, it is most likely composed of $\mathrm{Cr}_{3} \mathrm{Te}_{4}[20]$ doped with $\mathrm{Cd}$.

\section{TABLE I}

Composition of CdTe:Cr host matrix and needle-like defect, derived by means of HAADF STEM measurements.

\begin{tabular}{c|c|c|c|c|c|c}
\hline \hline \multirow{2}{*}{ Region } & \multicolumn{2}{|c|}{ Composition, [wt.\%] } & \multicolumn{3}{c}{ Composition, [at. \%] } \\
\cline { 2 - 7 } & $\mathrm{Cd}$ & $\mathrm{Te}$ & $\mathrm{Cr}$ & $\mathrm{Cd}$ & $\mathrm{Te}$ & $\mathrm{Cr}$ \\
\hline Defect & 4.44 & 71.21 & 24.35 & 3.71 & 52.36 & 43.93 \\
Matrix & 46.41 & 52.24 & 1.35 & 48.68 & 48.26 & 3.06
\end{tabular}

The only information about chromium separation in CdTe:Cr was reported by Nouruzi-Khorasani and Dobson [14]. They revealed triangular sub- $\mu \mathrm{m}$ precipitates composed of alloys of $\mathrm{Cr}$ and Te in the as-grown crystals, 
obtained by solvent evaporation method. After Cd-rich annealing the precipitates changed their morphology as well as composition and shaped into the needles containing more than $95 \%$ of chromium. At the same time, needle-like aggregates of several $\mathrm{mm}$ long, parallel to the $\{111\}$ planes, in sublimation grown CdTe:V and CdTe:Ti crystals was identified as $\mathrm{V}_{2} \mathrm{Te}_{3}$ and $\mathrm{Ti}_{2} \mathrm{Te}_{3}$ microinclusions, respectively [15]. It is known that inclusions in CdTe are originated by melt or solution droplet capture on the growth interface, whereas native precipitates are formed from the clusters of point defects during postgrown cooling due to retrograde character of cadmium and especially tellurium solubility in solid CdTe [4]. Typically, the lateral precipitates size is far less than $1 \mu \mathrm{m}$, while inclusions are much bigger, with dimensions up to several hundred $\mu \mathrm{m}$. In our case it is hard to refer the observed needle-like particles to inclusions or precipitates based only on the dimension criterion. We are now performing crystallographic investigations in order to determine their exact origin and formation mechanism.

\section{Summary and conclusions}

To conclude, we observed for the first time non-typical needle-like second phase macrodefects in heavily doped CdTe:Cr single crystals obtained by the modified PVT technique. We also determined that these defects are chromium telluride compound (most probably $\mathrm{Cd}$ doped $\mathrm{Cr}_{3} \mathrm{Te}_{4}$ ) and originate from the dopant separation in the grown crystals. Finally, it must be emphasized that formation of extrinsic ferromagnetic $\mathrm{Cr}-\mathrm{Te}$ phase, such as revealed $\mathrm{Cr}_{3} \mathrm{Te}_{4}$ one, can influence the magnetic properties of CdTe:Cr DMS.

\section{Acknowledgments}

This work is partially supported by the research project No. NN507264740 from the Polish National Science Centre.

\section{References}

[1] R. Triboulet, P. Siffert, CdTe and Related Compounds; Physics, Defects, Hetero- and NanoStructures, Crystal Growth, Surface and Applications. Part II: Crystal Growth, Surface and Applications, Elsevier Ltd., Amsterdam 2010.
[2] S. Sen, C.S. Liang, D.R. Rhiger, J.N. Stannard, H.F. Arlinghaus, J. Electron. Mater. 25, 1188 (1996).

[3] A.E. Bolotnikov, G.S. Camarda, Y. Cui, G. Yang, A. Hossain, K. Kim, R.B. James, J. Cryst. Growth 379, 46 (2013).

[4] J.H. Greenberg, J. Cryst. Growth 161, 1 (1996).

[5] R.J. Dinger, I.J. Fowler, Rev. Phys. Appl. 12, 135 (1977).

[6] H.N. Jayatirtha, D.O. Henderson, A. Burger, M.P. Volz, Appl. Phys. Lett. 62, 573 (1993).

[7] P. Rudolph, A. Engel, I. Schentke, A. Grochocki, J. Cryst. Growth 147, 297 (1995).

[8] R.U. Barz, P. Gille, J. Cryst. Growth 149, 196 (1995).

[9] F. Bisolli, N. Armani, G. Salviati, C. Ferrari, M. Zha, A. Zappetini, L. Zanotti, Phys. Status Solidi C 1, 735 (2004).

[10] N. Wang, P. Haasen, Phys. Status Solidi A 128, 37 (1991).

[11] J. Shen, D.K. Aidun, L. Regel, W.R. Wilcox, Mater. Sci. Eng. B 16, 182 (1993).

[12] T.J. Magee, J. Peng, J. Bean, Phys. Status Solidi A 27, 557 (1975).

[13] J.H. Narayanan, S.H. Rustomji, J. Electrochem. Soc. 126, 809 (1979).

[14] A. Nouruzi-Khorasani, P.S. Dobson, J. Cryst. Growth 92, 208 (1988).

[15] G. Kloess, M. Laasch, R. Shwarz, K.W. Benz, J. Cryst. Growth 146, 130 (1995).

[16] V.D. Popovych, I.S. Virt, F.F. Sizov, V.V. Tetyorkin, Z.F. Tsybrii (Ivasiv), L.O. Darchuk, O.A. Parfenjuk, M.I. Ilashchuk, J. Cryst. Growth 308, 63 (2007).

[17] A.G. Bluiett, U. Hommerich, R.T. Shan, S.B. Trivedi, S.W. Kutcher, C.C. Wang, J. Electron. Mater. 31, 806 (2002).

[18] W. Dobrowolski, J. Kossut, T. Story, in: Handbook of Magnetic Materials, Vol. 15, Elsevier Ltd., Amsterdam 2003.

[19] D.E. Sands, Introduction to Crystallography, W.A. Benjamin Inc., London 1969.

[20] G. Chattopadhyay, Phase Equilibr. 15, 431 (1994). 